\title{
Protective Effect of Trichilia monadelpha (TM) Thonn J.J. de Wilde in Trinitrobenzene Sulfonic Acid Induced Colitis in Rats
}

\author{
Oyindamola Abiodun ${ }^{1 *}$, Fisayo Ogunleye ${ }^{1}$, Elohor Ben-Upaka ${ }^{1}$ \\ 1 University of Ibadan, Pharmacology and Therapeutics, Ibadan/Oyo state, Nigeria
}

\begin{abstract}
Trichilia monadelpha (TM) is a plant commonly used to treat gastrointestinal disorders, inflammatory diseases and pain. This study evaluated the effect of aqueousmethanol extract of stem bark of TM (MeTM) on trinitrobenzene sulfonic acid (TNBS) induced rat colitis. Thirty male Wistar rats (180-200 g) were randomly distributed into six groups $(\mathrm{n}=5)$ : non-colitic, colitic untreated or treated with prednisolone (2 $\mathrm{mg} / \mathrm{kg}$ ) and MeTM (100 - $400 \mathrm{mg} / \mathrm{kg}$, given orally 2 days pre- and 7 days post-induction). Response to treatment was assessed. GC-MS analysis of MeTM was done.

Prednisolone and MeTM (200 \& $400 \mathrm{mg} / \mathrm{kg}$ ) significantly reduced colonic damage scores, weight/length ratio and MPO activity in colitic rats compared to untreated group ( $\mathrm{p} \leq 0.05$ ). Similarly, MeTM and prednisolone significantly prevented depletion of GSH levels in treated rats compared to untreated colitic rats (p, o.0001). The most abundant compound is Oleic acid (79\%) followed by 6-Octadecanoic acid (3.69\%).
\end{abstract}

Keywords: Trichilia monadelpha, colitis, glutathione, superoxide dismutase, myeloperoxidase.

\section{INTRODUCTION}

Inflammatory bowel disease (IBD) comprises of two main types of chronic relapsing inflammatory intestinal disorders: Crohn's disease (CD) and ulcerative colitis (UC) ${ }^{1}$. Among other factors, these disorders of the gut are believed to occur in genetically predisposed individuals due to exposure of unknown environmental and microbial agents ${ }^{2}$. Pharmacological therapies for IBD usually include well established drugs recognized as conventional therapies. This is made up of five distinct pharmacological classes: aminosalicylates, antibiotics,

*Corresponding author: Oyindamola Abiodun, e-mail: oyindamolaabiodun1@gmail.com Oyindamola Abiodun ORCID Number: 0000-0002-6629-3016

Fisayo Ogunleye ORCID Number: 0000-0003-1549-7315

Elohor Ben-Upaka ORCID Number: 0000-0001-8195-839X

(Received 08 January 2020, accepted 26 January 2020) 
corticosteroids, thiopurines and folic acid antagonists such as methotrexate ${ }^{3,4}$. Recently, a number of additional approaches to IBD therapy, such as new target molecules for biological agents and cellular therapy have shown promising results ${ }^{4}$. However, the use of these drugs is accompanied by a certain number of side effects, like the risks of infection, and malignancy ${ }^{5-7}$. Thus, there is need for the search for new therapies that will be able to treat the various presentations in IBD and at the same time have reduced side effects.

Thus effort in this study is to explore medicinal plant for the treatment of experimentally induced colitis. Trichilia monadelpha previously known as Trichilia heudelotii ${ }^{8}$ is used traditionally in Nigeria and Ghana for the management of diverse disease conditions. The plant is commonly known as tanduru/tanduro in Ghana ${ }^{8}$ and akorere in Nigeria ${ }^{9}$. The bark is used to treat gastrointestinal complaints, cough, gonorrhoea, syphilis ${ }^{10-11}$ and skin ulcer ${ }^{8}$. The bark is also used as an anthelmintic, aphrodisiac, abortifacient, antiplasmodial ${ }^{8,11}$ and as an antiinflammatory and analgesic agent in the management of inflammatory conditions including arthritis ${ }^{11-12}$. Other parts, such as the leaves and roots have many other medicinal uses ${ }^{11}$. The beneficial effect of $T$. monadelpha on a rat model of colitis was embarked on, based on the folkloric evidence that T. monadelpha is useful for the treatment of inflammatory and gastrointestinal disorders.

\section{METHODOLOGY}

\section{Chemicals and Reagents}

All chemicals used in this experiment were purchased from Sigma-Aldrich ${ }^{\circledR}$, UK, unless otherwise stated.

\section{Plant collection and authentication}

Stem bark of Trichilia monadelpha was collected from the Vice Chancellor's lodge, University of Ibadan. The plant was identified and authenticated at Forestry Research Institute of Nigeria (FRIN), Jericho, Ibadan. The voucher specimen was given FHI number 110380 .

\section{Plant extraction}

Four hundred and ninety-six grams (496 g) of the stem bark of T. monadelpha was air-dried and pulverized. The dried plant material was extracted in $70 \%$ methanol by maceration at room temperature for 72 hours. Thereafter, the extract was filtered and solvent removed using rotary evaporator at $40^{\circ} \mathrm{C}$ and under reduced pressure. Percentage yield was calculated and extract stored in the refrigerator at $4^{\circ} \mathrm{C}$ till needed for analysis. 


\section{Experimental animals}

A total of thirty male Wistar rats weighing between 180 and 200 grams, raised in the animal house of Malaria Research Laboratory, Institute for Advanced Medical Research and Training (IMRAT), College of Medicine, University College Hospital (UCH), Ibadan were used for the study. The rats were kept under room temperature and fed with standard rat pellets and water ad libitum. Experimental rats were randomly distributed into six groups of five rats each. Three of the six groups were pre-treated with 100,200 and $400 \mathrm{mg} / \mathrm{kg}$ of methanol extract of stem bark of TM (MeTM) orally for two days before induction of colitis and thereafter the extract was administered daily for 7 days post colitis. The remaining three groups served as positive control (Daily oral administration of $2 \mathrm{mg} / \mathrm{kg}$ of prednisolone for 7 days post-colitis); untreated colitic (negative control) and healthy non-colitic rats.

\section{Ethical consideration}

Experimental procedures and protocols used in this study conform to the "Guide to the care and use of animals in research and teaching" (NIH publications number 85-93 revised in 1985).

\section{Induction of colitis}

Colitis was induced using a previously reported method ${ }^{16}$. Food and water were withdrawn 18 hours prior to induction of colitisand the animals were anesthetized with ketamine/diazepam $(50 / 2.5 \mathrm{mg} / \mathrm{kg})$. Colitis was induced by a single intracolonic administration of Trinitrobenzene sulphonic acid $(40 \mathrm{mg} / \mathrm{mL})$ into the distal colon by means of a soft pediatric catheter introduced $8 \mathrm{~cm}$ into the anus and the animals were kept in a head down position for 5 minutes. They were returned to their cages after recovering from the anesthesia and given free access to food and water.

\section{Assessment of colonic damage and response to treatment}

All the rats were euthanized on day 7 post-colitic induction with an overdose of ether. Once the rats were sacrificed, the distal colon of each animal was excised and luminal contents flushed out with cold normal saline. Thereafter, each colon was opened by an incision along the mesenteric border. The weight and length of each of the colon was measured and scored. Macroscopic physical damage was assessed on a scale of $0-10^{17}$.

\section{Biochemical assays}

A known weight of freshly excised tissue was homogenized in $10 \mathrm{mM}$ hexadecyltrimethyl ammonium bromide (HTAB) buffer $(50 \mathrm{mg} / \mathrm{mL})$. The supernatant 
from the homogenized samples was used for determination of total glutathione content (GSH), superoxide dismutase (SOD) and Myeloperoxidase activity (MPO). Reduced glutathione (GSH) level was estimated according to the method described by Anderson ${ }^{18}$ and the results were expressed as nanomoles per gram of wet tissue. The SOD activity was determined by the method of Mistra and Fridovich ${ }^{19}$ and the results were expressed as unit per gram tissue. Myeloperoxidase activity (MPO) was measured according to a method previously described $^{20}$ and the results were expressed as MPO units per gram of wet tissue; one unit of MPO activity was defined as that degrading $1 \mathrm{mmol}$ hydrogen peroxide $/ \mathrm{min}$ at $25^{\circ} \mathrm{C}$.

\section{Determination of total phenolic content of MeTM}

The total phenolic content (TPC) of MeTM was determined by the spectrophotometric method ${ }^{13}$. Briefly, o.1 $\mathrm{mL}$ of MeTM ( $1 \mathrm{mg} / \mathrm{mL}$ in phosphate buffer), was mixed with $0.1 \mathrm{ml}$ of Folin-ciocalteu's phenol reagent in a test tube. After $5 \mathrm{~min}$, $1 \mathrm{ml}$ of $7 \% \mathrm{Na}_{2} \mathrm{CO}_{3}$ solution and $1.3 \mathrm{ml}$ of deionized distilled water were added to the mixture and the mixture was thoroughly mixed. The mixture was incubated in the dark for 90 min at $23{ }^{\circ} \mathrm{C}$, after which the absorbance was read against a blank without the extract at $750 \mathrm{~nm}$. The determination of TPC was done in triplicate. The TPC was estimated from gallic acid calibration curve and expressed as milligrams of gallic acid equivalents (GAE) per $100 \mathrm{~g}$ of dried sample.

\section{Determination of total flavonoid content of MeTM}

Total flavonoid content (TFC) was determined using aluminium chloride in a colorimetric method ${ }^{14}$. A volume of $0.3 \mathrm{~mL}$ of MeTM $(1 \mathrm{mg} / \mathrm{mL})$ was dispensed into a test tube and $3.4 \mathrm{~mL}$ of $30 \%$ methanol, $0.15 \mathrm{~mL}$ of $\mathrm{NaNO}_{2}(0.5 \mathrm{M})$ and $0.15 \mathrm{~mL}$ of $\mathrm{AlCl}_{3} \cdot 6 \mathrm{H}_{2} \mathrm{O}(\mathrm{o} .3 \mathrm{M})$ were added and mixed. After $5 \mathrm{~min}, 1 \mathrm{~mL}$ of $\mathrm{NaOH}(1 \mathrm{M})$ was added. The solution was thoroughly mixed and the absorbance of the mixture was measured against blank without extract at $506 \mathrm{~nm}$. The TFC was estimated from rutin calibration curve and TFC was expressed as milligrams of rutin equivalents per $100 \mathrm{~g}$ of dried fraction (mg RE/g of sample).

\section{Chemical composition of MeTM using Gas Chromatograhy-Mass Spectrometry}

The chemical composition of the MeTM was identified using the GC-MS according to a previously described method ${ }^{15}$ using Agilent technologies 7890 GC system with an Agilent technology 5975 Mass Spectrometry Detector. The automatic injector injects the $1 \mu \mathrm{L}$ of MeTM into the liner. The initial oven temperature of $80^{\circ} \mathrm{C}$ wasprogrammed to hold for 1 minute, it increased by $10^{\circ} \mathrm{C}$ per minute to the final temperature of $240^{\circ} \mathrm{C}$ to hold for 6 minutes. The mobile 
phase [a carrier gas (Helium, 99.99\% purity)] pushed the sample from the liner into the column (HP5 MS with length $30 \mathrm{~m}$, internal diameter $0.320 \mathrm{~mm}$ and thickness is $0.25 \mu \mathrm{m}$ ) where separation takes place into different components at different retention time. The compounds were identified by comparison of their retention time and mass spectra fragmentation against the National Institute Standard and Technology (NIST) mass spectra library of GC-MS data system.

\section{Statistical Analysis}

All results were expressed as mean \pm SEM (standard error of mean). Differences between means were tested for statistical significance using a one way analysis of variance (ANOVA) with the turkey post hoc test. Statistical analyses were carried out with Graph Pad Prism version 6.0 and statistical significance set as $\mathrm{p}<0.05$.

\section{RESULTS AND DISCUSSION}

Macroscopic characteristics of colon of the colitic rats such as hyperaemia, swelling, oedema, ulceration and necrosis were scored and referred to as damage score (Table 1). Treatment of colitic rats with MeTM at $400 \mathrm{mg} / \mathrm{kg}$ ( $4.5 \pm 0.3$ ) and prednisolone at $2 \mathrm{mg} / \mathrm{kg}(2.3 \pm 0.3)$ resulted in lower colonic damage score in comparison to the colon of untreated colitic rats $(6.0 \pm 0.4, p \leq 0.05$, Table 1$)$. This beneficial effect was associated with reduced colonic weight/length ratio observed in colitic rats treated with MeTM at $400 \mathrm{mg} / \mathrm{kg}$ dose $(143.6 \pm 5.2 \mathrm{mg} / \mathrm{cm})$ and prednisolone $(140.5 \pm 3.5 \mathrm{mg} / \mathrm{cm})$ in comparison to the colonic weight/length ratio of the untreated colitic animals $(166.8 \pm 4.8 \mathrm{mg} / \mathrm{cm}, \mathrm{p} \leq 0.01$, Table 1$)$.

Table 1. Macroscopic colon damage index and colonic weight/length ratio of colitic rats, noncolitic rats and treatment groups

\begin{tabular}{c|cc}
\hline Treatment Groups & Damage score (0-10) & $\begin{array}{c}\text { Colonic weight/length ratio } \\
\text { (mg/cm) }\end{array}$ \\
\hline & & \\
Healthy (Non-colitic) & $0.0 \pm 0.0^{*}$ & $91.3 \pm 5.8^{*}$ \\
Negative control & $6.0 \pm 0.4$ & $166.8 \pm 4.8$ \\
Prednisolone (2mg/kg) & $2.3 \pm 0.3^{* \#}$ & $140.5 \pm 3.5^{\S}$ \\
T. monadelpha & $5.0 \pm 0.3$ & $160.8 \pm 8.2$ \\
$100 \mathrm{mg} / \mathrm{Kg}$ & $5.2 \pm 0.2$ & $159.3 \pm 9.6$ \\
$200 \mathrm{mg} / \mathrm{Kg}$ & $4.5 \pm 0.3^{*}$ & $143.6 \pm 5.2^{\S \S}$ \\
$400 \mathrm{mg} / \mathrm{Kg}$ & & \\
& & \\
\hline
\end{tabular}

${ }^{*}$ Healthy vscolitic and treatment group $\mathrm{p}<0.05$

Damage score ${ }^{\# \#}$ Prednisolone \& ${ }^{\#} 400 \mathrm{mg} / \mathrm{Kg}$ vs untreated colitic group $\mathrm{p}<0.05$

Colon/weight length ratio ${ }^{\S}$ Prednisolone $\& ~^{\S} 400 \mathrm{mg} / \mathrm{Kg}$ vs untreated colitic group $\mathrm{p} \leq 0.01$ 
Furthermore a significant reduction in leucocytes infiltration indicated by decreased colonic MPO activity was an additional beneficial effect of MeTM observed in colon of colitic rats $(3.70 \pm 0.28-4.41 \pm 0.32 \mathrm{U} / \mathrm{mg}$ tissue $)$ and prednisolone (3.77 $\pm 0.09 \mathrm{U} / \mathrm{mg}$ tissue) in comparison with untreated colitic rats $(6.03 \pm 0.35 \mathrm{U} / \mathrm{mg}$ tissue, $\mathrm{p} \leq 0.005$, Figure 1$)$. The two higher doses of MeTM $200 \& 400 \mathrm{mg} / \mathrm{kg}(83.78 \pm 2.16, \& 82.37 \pm 1.92 \mathrm{nmol} / \mathrm{mg}$ tissue $)$ and prednisolone (130.13 $\pm 10.15 \mathrm{nmol} / \mathrm{mg}$ tissue, Figure 2) significantly prevented the depletion of colonic GSH level in colitic rats in comparison with untreated colitic rats $(56.96 \pm 9.19 \mathrm{nmol} / \mathrm{mg}$ tissue, $\mathrm{p} \leq 0.02)$. In contrast, The MeTM was unable to significantly prevent depletion of SOD level (0.005 \pm 0.001 to $0.006 \pm 0.001$ $\mathrm{U} / \mathrm{mg}$ tissue) when compared with untreated colitic rats (0.003 $\pm 0.002 \mathrm{U} / \mathrm{mg}$ tissue). In contrast, the prednisolone prevented the depletion of SOD (o.034 \pm $0.001 \mathrm{U} / \mathrm{mg}$ tissue, $\mathrm{p}<0.0001$, Figure 3).

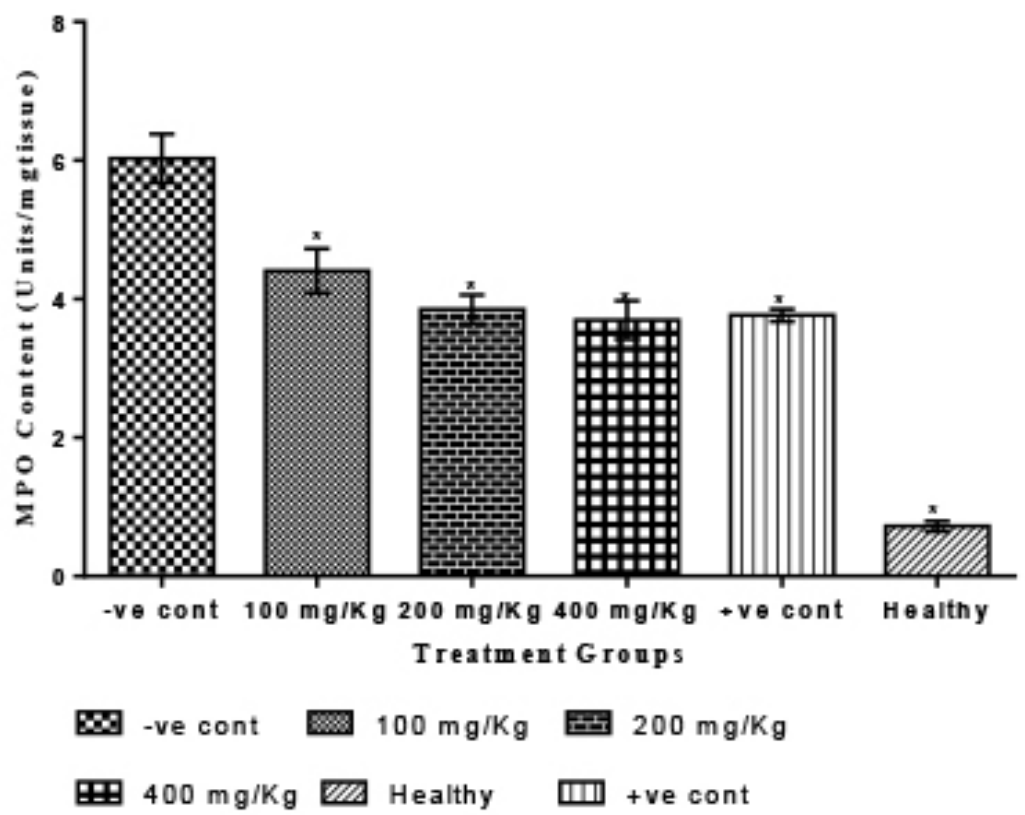

Figure 1. Effect of methanolic extract of T. monadelpha on colonic MPO content in colon tissue

*All the extract treated groups and prednisolone group are significantly different from the colitic group $(\mathrm{p} \leq \mathrm{0.05})$. 


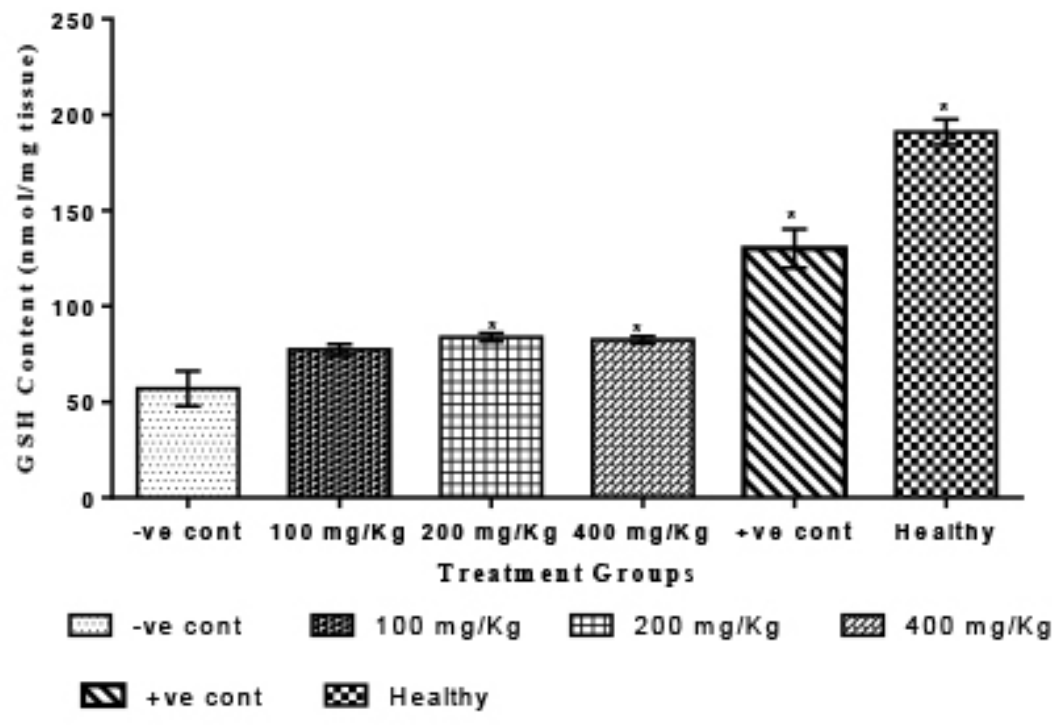

Figure 2. Effect of methanolic extract of T. monadelpha on the level of colonic GSH in a rat model of colitis

*200, $400 \mathrm{mg} / \mathrm{Kg}$ and prednisolone treated groups (positive control) showed a significant difference when compared with the colitic group ( $\mathrm{p} \leq \mathrm{0.05})$.

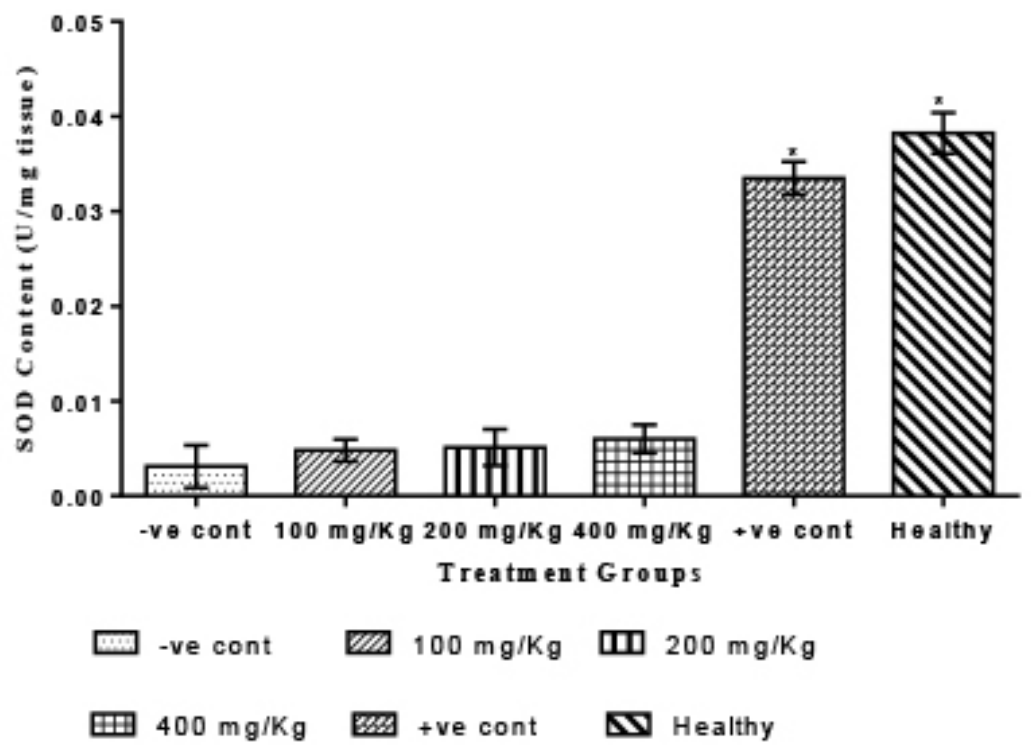

Figure 3. Effect of methanolic extract of T. monadelpha on the level of colonic SOD in a rat model of colitis. 
Values are means \pm SEM, the groups treated with the various doses of the plant extract does not show significant difference when compared to the colitic group.

*, the positive control group showed a significant difference compared to the negative control (colitic group) ( $\mathrm{p}<0.0001)$.

In this study, MeTM at the highest dose tested significantly ameliorates colonic damage and reduce weight/length ratio. Severe colonic damage and high colonic weight/length ratio are associated with TNBS induced colitis in rats ${ }^{21}$. The macroscopic observation of resolution of intestinal oedema and colonic damage in the colon of colitic rats at 200 and $400 \mathrm{mg} / \mathrm{kg} \mathrm{MeTM}$ signified that MeTM produce beneficial effect against intestinal inflammation. Furthermore, the activity of myeloperoxidase (MPO) an enzyme found in azurotrophilic of polymorphonuclear neutrophils and macrophages, widely used as an index for the severity of intestinal inflammation ${ }^{22-23}$ was used to evaluate the intestinal antiinflammatory activity of MeTM. A reduction in MPO activity is considered as a marker of tissue recovery while an increase activity is indicative of intestinal inflammation. An increase in activity of the enzyme was observed in untreated colitic rats in this study and previous studies ${ }^{1,24,25}$. The administration of MeTM to colitic rats in this study was able to produce a moderate but significant reduction in the colonic MPO activity. This observation suggests that MeTM was able to inhibit granulocyte infiltration, thereby reducing the activity of MPO. To further explore the beneficial effect of MeTM in colitis, the ability of MeTM to control oxidative stress was investigated. Oxidative stress which is due to the activity of reactive oxygen species/nitrogen species (ROS/RNS) has been implicated in a number of human diseases, including inflammatory bowel diseases ${ }^{26}$. The loss of antioxidant defences may severely compromise the inflamed mucosa and render it more susceptible to injury and make recovery of inflamed tissue difficult. Antioxidant agents have been shown to prevent IBD in animal models and in human disease ${ }^{27,28}$. The colonic content of the antioxidant peptide glutathione (GSH) was depleted in untreated colitic rats; this is probably due to the oxidative stress that occurs in the inflamed tissues of the colon. Interestingly, administration of 200 and $400 \mathrm{mg} / \mathrm{kg}$ doses of MeTM significantly prevented the depletion of colonic glutathione in the colitic rats, thus maintaining the colonic antioxidant status. However, all the doses of MeTM administered was not able to significantly prevent the depletion of colonic SOD in colitic rats. The partial antioxidant activity of MeTM observed in this study might be the reason for its overall moderate beneficial effect. 
Table 2. Identification of chemical components of methanol extract of T. monadelpha using GC-MS

\begin{tabular}{|c|c|c|c|c|}
\hline Peak No. & Compound & RT (min) & $\%$ abundance & M/Z Value \\
\hline 1 & cis-Vaccenic acid & 16.02 & 2.57 & 282 \\
\hline 2 & Octadec-9-enoic acid & 16.29 & 0.82 & 282 \\
\hline 3 & 9-0ctadecenoic acid (E)- & 16.62 & 3.69 & 282 \\
\hline 4 & $\begin{array}{l}\text { 13-0ctadecenoic acid, methyl } \\
\text { ester }\end{array}$ & 19.19 & 3.34 & 296 \\
\hline 5 & 6-0ctadecenoic acid, (Z)- & 19.28 & 0.36 & 282 \\
\hline 6 & $\begin{array}{l}\text { i-Propyl 11,12-methylene- } \\
\text { octadecanoate }\end{array}$ & 19.45 & 1.48 & 338 \\
\hline 7 & $\begin{array}{l}\text { 9-0ctadecenoic acid (Z)-2,3- } \\
\text { dihydroxypropyl ester }\end{array}$ & 19.49 & 0.60 & 356 \\
\hline 8 & Oleic acid & 20.04 & 79.14 & 576 \\
\hline 9 & Pyridine-3-carboxamide & 20.53 & 1.42 & 281 \\
\hline 10 & n-Propyl 11-octadecenoate & 20.74 & 0.31 & 324 \\
\hline 11 & trans-9-0ctadecenoic acid & 20.76 & 0.28 & 352 \\
\hline
\end{tabular}

RT - retention time, $\mathrm{M} / \mathrm{Z}$ - Mass to charge ratio

The percentage yield, following the extraction of MeTM in 70\% methanol was $8 \%$. The total phenolic and flavonoid content of MeTM were $801.58 \pm 0.48 \mathrm{mg}$ gallic acid equivalent/g and $308.38 \pm 0.48 \mathrm{mg}$ rutin equivalent/g respectively. In addition, 11 compounds were identified in the GC-MS analysis of MeTM. The chromatogram of the different compounds is shown in Figure 4 -14. 


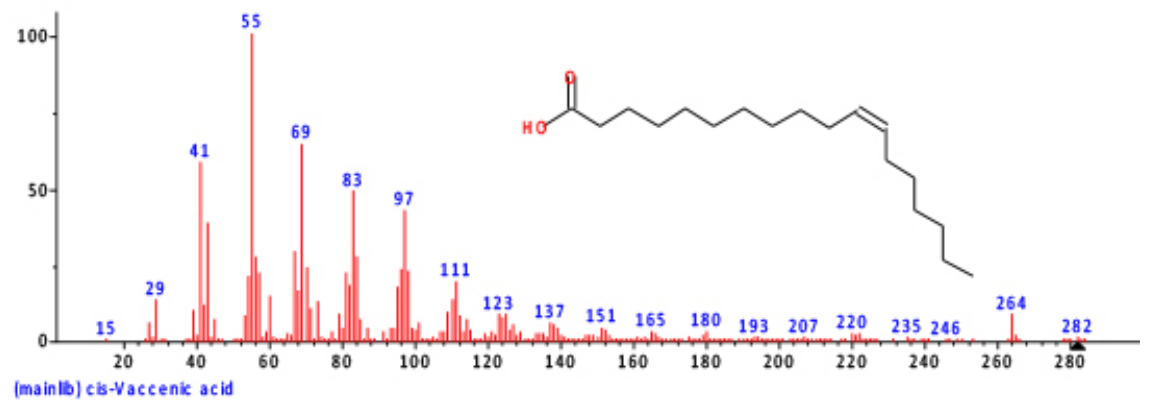

Figure 4. Mass spectra of cis-Vaccenic acid, a plot of relative abundance against mass to charge ratio

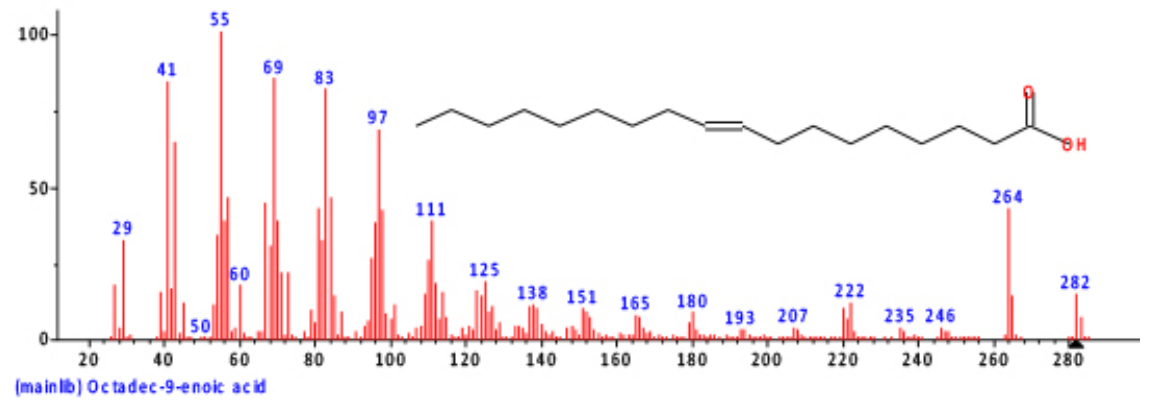

Figure 5. Mass spectra of Octadec-9-enoic acid, a plot of relative abundance against mass to charge ratio

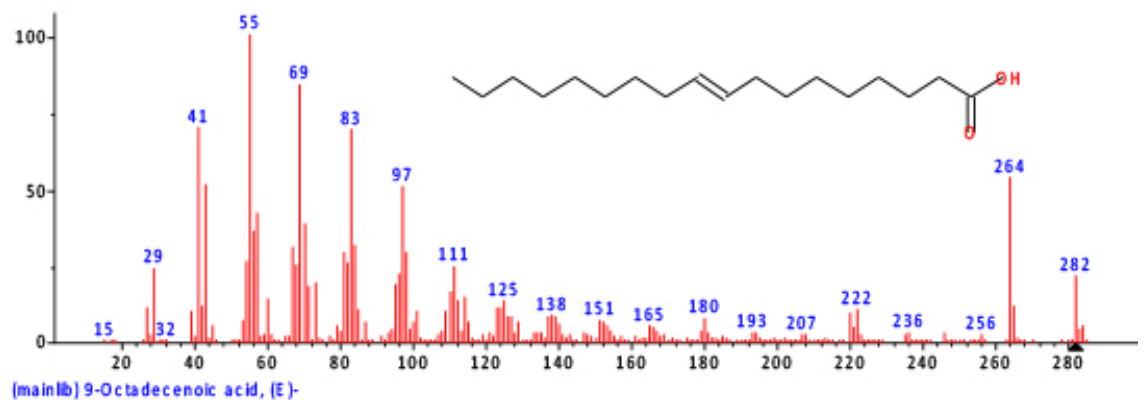

Figure 6. Mass spectra of 9-0ctadecenoic acid, (E)- a plot of relative abundance against mass to charge ratio 


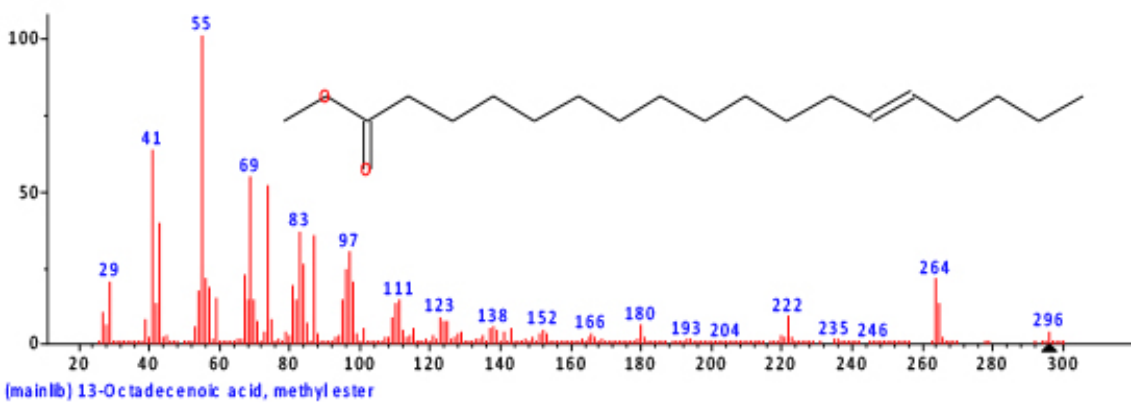

Figure 7. Mass spectra of 13-0ctadecenoic acid, methyl ester, a plot of relative abundance against mass to charge ratio

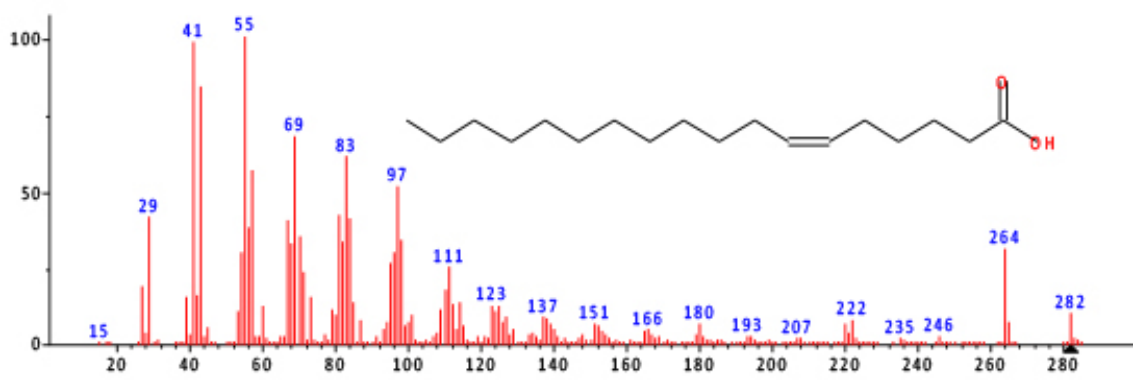

(main lb) 6-0ctadecenoic acid, $(z)$.

Figure 8. Mass spectra of 6-0ctadecenoic acid, (Z)-, a plot of relative abundance against mass to charge ratio

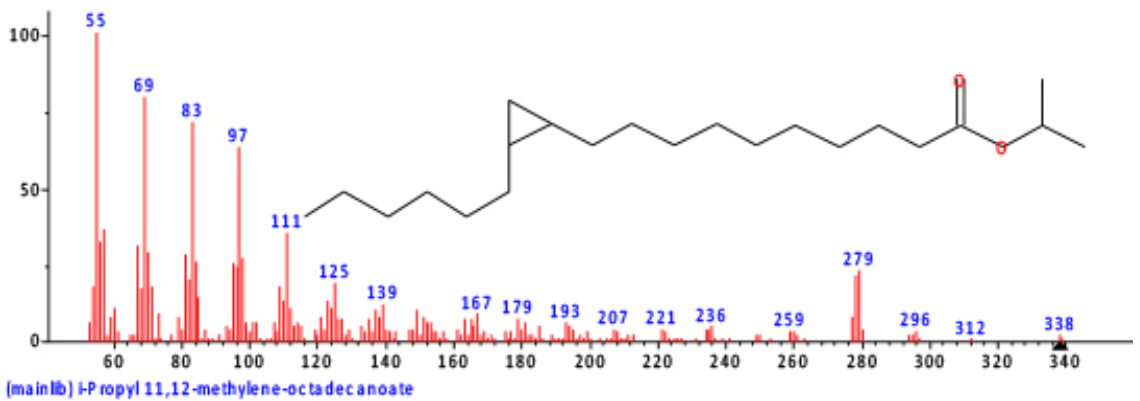

Figure 9. Mass spectra of i-Propyl 11,12-methylene-octadecanoate acid, a plot of relative abundance against mass to charge ratio 


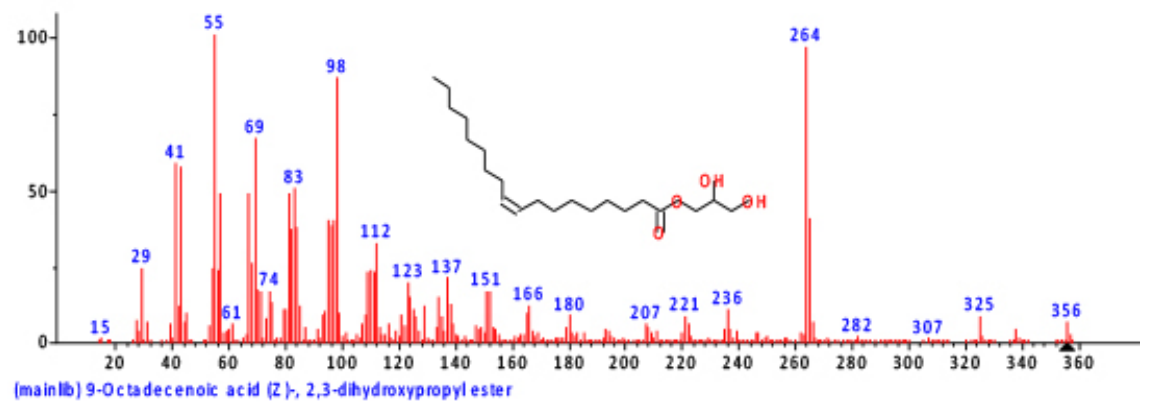

Figure 10. Mass spectra of 9-0ctadecenoic acid, a plot of relative abundance against mass to charge ratio

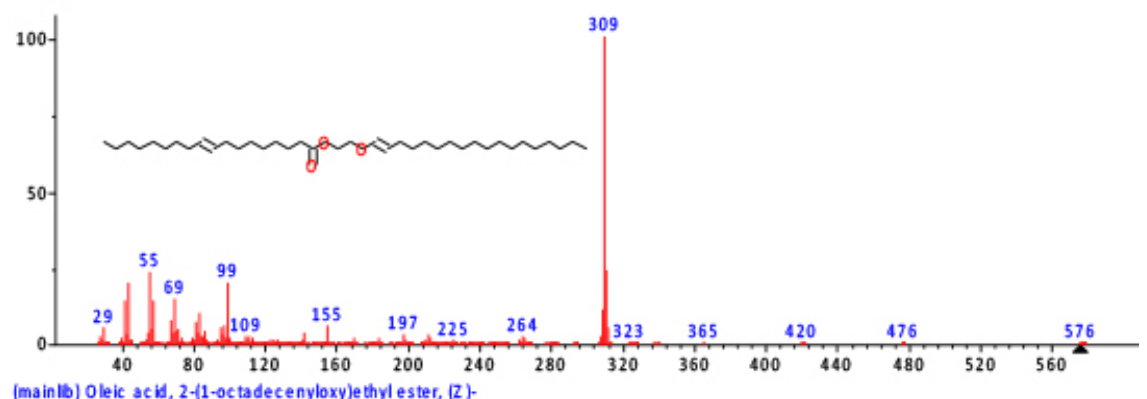

Figure 11. Mass spectra of Oleic acid, a plot of relative abundance against mass to charge ratio

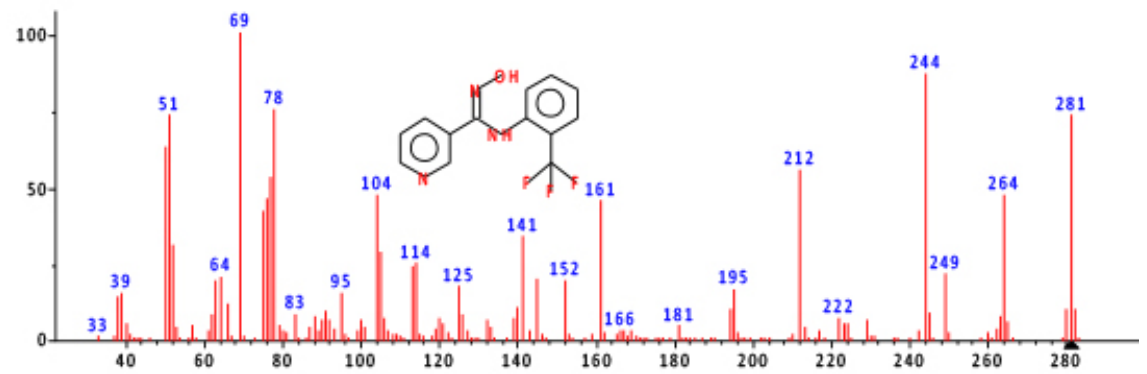

[ma in Ib] P yrid ine-3-carboxamide, oxime, $N$ - $\{2$-trifluorome thylphenyl)-

Figure 12. Mass spectra of Pyridine-3-carboxamide, a plot of relative abundance against mass to charge ratio 


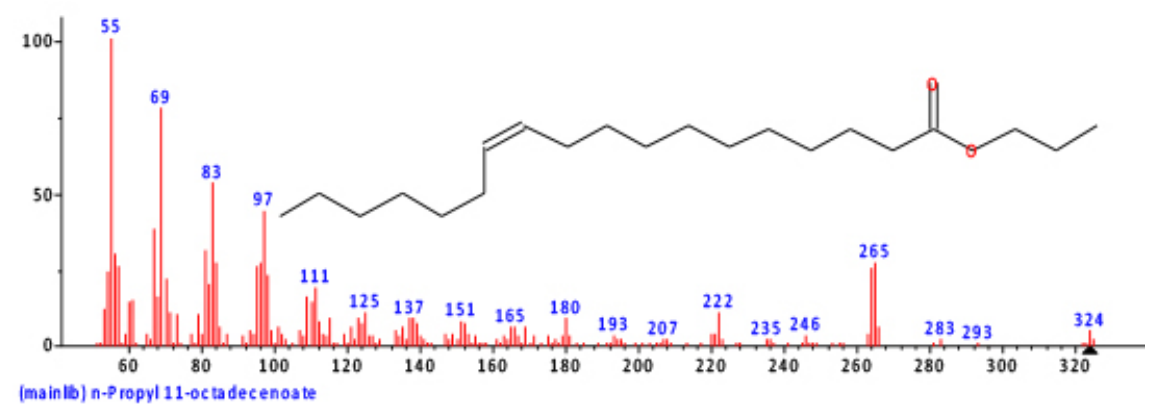

Figure 13. Mass spectra of n-Propyl 11-octadecenoate, a plot of relative abundance against mass to charge ratio

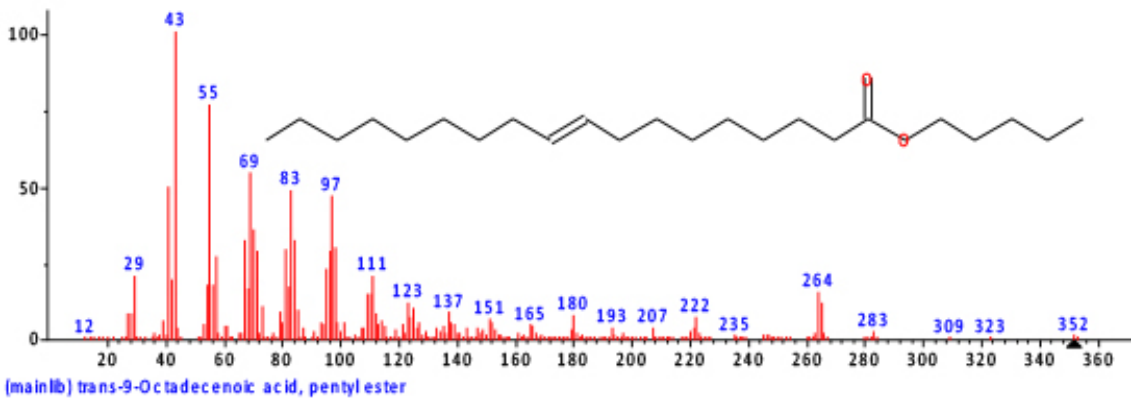

Figure 14. Mass spectra of trans-9-0ctadecenoic acid, pentyl ester a plot of relative abundance against mass to charge ratio

Oleic acid (79\%), 6-Octadecenoic acid (3.69\%), 13-Octadecenoic acid, methyl ester (3.3\%), cis-Vaccenic acid (2.57\%) were the most abundant compounds. Oleic acid, an Omega 9 monounsaturated fatty acid has been shown to produce an increase in the survival rate, decreased neutrophil accumulation, lowered plasma TNF- $\alpha$, prostaglandin $\mathrm{E}_{2}$ and leukotriene $\mathrm{B}_{4}$ levels in the peritoneal cavity after LPS-induced endotoxic shock in rodents ${ }^{29}$. Oleic acid is a main constituent of Olive oil. Octadec-6-enoic acid also known as petroselinic acid is a fatty acid classified as a monounsaturated omega-12 fatty acid. It occurs naturally in several animal and vegetable fats and oil. Cis-Vaccenic acid is a naturally occurring trans-fatty acid. It is found mostly in human milk. Mammals convert it into rumeric acid a conjugated linoleic acid $\mathrm{CLA}^{30}$. Some studies have shown a direct association between vaccenic acid and reduced risk of cancer, such as breast and prostate cancer. In a 16-week trial involving rodent models, a diet enriched with vaccenic acid significantly improved immune function ${ }^{31-35}$. The other prominent compound found in the extract is 13-Octadecenoic acid methyl ester also have anti-inflammatory and cancer preventive activities. 
Consequently, The presence of the phytochemicals in this plant might contribute to the beneficial effect of methanol extract of $T$. monadelpha in the rat colitis observed in this study. Treatment with methanol extract of T. monadelpha resulted in prevention of depletion of glutathione and inhibition of MPO activity in TNBS-induced colitis.

\section{CONFLICT OF INTEREST}

The authors declares no conflict of interest

\section{ACKNOWLEDGEMENT}

The authors acknowledge the technical assistance of Mrs Braimah during the course of the study. 


\section{REFERENCES}

1. Singh, U.P.; Singh, N.P.; Busbee, B. Alternative medicines as emerging therapies for inflammatory bowel diseases. Int. Rev. Immunol. 2012, 31, 66-84.

2. Dharmani, P.; Chadee, K. Biologic therapies against inflammatory bowel disease: a dysregulated immune system and the cross talk with gastrointestinal mucosa hold the key. Curr. Mol. Pharmacol. 2008, 1, 195-212.

3. Taylor, K.M.; Irving, P.M. Optimization of conventional therapy in patients with IBD. Nat. Rev. Gastroenterol. Hepatol. 2011, 8, 646-656.

4. Sales-Campos, H.; Basso, P.J.; Alves, V.B.F.; Fonseca, M.T.C.; Bonfa, G.; Nardini, V.; Cardoso, C.R.B. Classical and recent advances in the treatment of inflammatory bowel diseases. Braz. J. Med. Biol. Res. 2015, 48, 96-107.

5. Toruner, M.; Loftus, E.V.; Harmsen, W.S. Risk factors for opportunistic infections in patients with inflammatory bowel disease. Gastroenterol. 2008, 134, 929-36.

6. Lichtenstein, G.R.; Rutgeerts, P.; Sandborn, W.J. A pooled analysis of infections, malignancy, and mortality in infliximab- and immunomodulator treated adult patients with inflammatory bowel disease. Am. J. Gastroenterol. 2012, 107, 1051-63.

7. Triantafillidis, J.K.; Stanciu, C. Inflammatory bowel disease: etiopathogenesis, diagnosis, treatment. 4th Edition, "Technogramma", Athens, Greece 2012.

8. Abbiw, D.K. Useful Plants of Ghana; Richmond Intermediate Technology Publications and The Royal Botanic Gardens Kew, London. 1990, 154-157.

9. Odugbemi, T.; Odunayo, A. Medicinal Plants According to Family Names. Outlines and Pictures of Medicinal Plants from Nigeria. T. Odugbemi. Lagos: University of Lagos Press. 20o8, $117-146$.

10. Irvine, F.R. Woody Plants of Ghana. London: Oxford University Press. 1961, 143-144.

11. Lemmens, R.H.M.J. Plant Resources of Tropical Africa. "Trichilia monadelpha (Thonn) J.J.de Wilde". 1n: D. Louppe, A. A. Oteng-Amoako and M. Brink, PROTA Foundation Wageningen, Netherlands/Backhuys Publishers, Leiden, Netherlands/CTA, Wageningen, Netherlands. 2008, $7,561-563$.

12. Mshana, N.R.; Abbiw, K.; Addae-Mensah, I.; Adjanohoun, E.; Ahyi, M.R.A.; Ekpere, J.A.; Enow-Orock, E.G.; Gbile, Z.O.; Noamesi, G.K.; Odei, M.A.; Odunlami, H.; Oteng-Yeboah, A.A.; Sarpong, K.; Soforowa, A.; Tackie, A.N. Traditional Medicine and Pharmacopoeia. Contribution to the Revision of Ethnobotanical and Floristic Studies in Ghana. Accra: Organization of African Unity/Scientific, Technical \& Research Commision. 2ooo, 676-677.

13. Kim, D.; Jeong, S.W.; Lee, C.Y. Antioxidant capacity of phenolic phytochemicals from various cultivars of plums. J. Food Chem. 2003, 81, 321-326.

14. Park, Y.S.; Jung, S.T.; Kang S.G.; Heo, B.K.; Arancibia, A.P.; Toledo F.; Drzewiecki, J.; Gorinstein, S. Antioxidants and proteins in ethylene-treated kiwi fruits. Food Chem. 2oo8, 107, 640-648.

15. Wangchuk, P.; Severine, N.; Catherine, S.; Paul, A.K.; Stephen, G.P.; Alex, L. Diterpenoid alkaloids of Aconitum laciniatum and mitigation of inflammation by $14-O$-acetylneoline in a murine model of ulcerative colitis. Sci. Rep. 2015, 5, 128-45.

16. Morris, G.P.; Beck, P.L.; Herridge, M.S.; Depew, W.T.; Szewczuk, M.R.; Wallace, J.L. Hapten-induced model of chronic inflammation and ulceration in the rat colon. Gastroenterol. 1989, 96, 795-803. 
17. Camuesco, D.; Peran, L.; Comalada, M.; Nieto, A.; Di Stasi, L.C.; Rodriguez-Cabezas, M.E.; Concha, A.; Zarzuelo, A.; Galvez, J. Preventative effects of lactulose in the trinitrobenzene sulphonic acid model of rat colitis. Inflamm Bow. Dis. 2005, 11, 265-71.

18. Anderson, M.E. Determination of glutathione and glutathione disulfide in biological samples. Method Enzymol. 1985, 113, 548-555.

19. Misra, H.P.; Fridovich, I. The role of superoxide anion in the autoxidation of epinephrine and a simple assay for superoxide dismutase. J Biol Chem. 1972, 247, 3170-5.

20. Krawisz, J.E.; Sharon, P.; Stenson, W.F. Quantitative assay for acute intestinal inflammation based on myeloperoxidase activity assessment of inflammation in rat and hamster models. Gastroenterology. 1984, 87, 1344-1350.

21. Abiodun, O.O.; Rodríguez-Nogales, A.; Algieri, F.; Gomez-Caravaca, A.M.; Segura-Carretero, A.; Utrilla, M.P.; Rodriguez-Cabezas, M.E.; Galvez, J. Anti-inflammatory and immunomodulatory activity of an ethanolic extract from the stem bark of Terminalia catappa L. (Combretaceae): in vitro and in vivo evidences. J. Ethnopharm. 2016, 192, 309-319.

22. Galvez, J.; Garrido, M.; Rodriguez-Cabezas, M.E. The intestinal anti-inflammatory activity of UR-12746S on reactivated experimental colitis is mediated through downregulation of cytokine production. Inflamm. Bowel Dis. 2003, 9, 363-371.

23. Masoodi, I.; Tijjani, B.M.; Wani, H.; Hassan, N.S.; Khan, A.B.; Hussain, S. Biomarkers in the management of ulcerative colitis: a brief review. Ger. Med. Sci. 2011, 9, 03.

24. Algieri, F.; Rodríguez-Nogales, A.; Garrido-Mesa, N. Intestinal anti-inflammatory effects of oligosaccharides derived from lactulose in the trinitrobenzene sulfonic acid model of rat colitis. J. Agric. Food Chem. 2014, 62, 4285-97.

25. Abiodun, O.O.; Oshinloye, A.O. Carpolobia lutea G. Don (Polygalaceae) Inhibits inflammation and oxidative stress in an acetic acid induced model of rat colitis. Drug Res (Stuttg). 2017, 67, 20-24.

26. Piechota-Polanczyk, A.; Fichna, J. Review article: the role of oxidative stress in pathogenesis and treatment of inflammatory bowel diseases. Naunyn-Schmiedeberg's Arch. Pharmacol. 2014, 387, 605-620.

27. Shih, D.Q.; Targan, S.R. Immunopathogenesis of inflammatory bowel disease. World $J$ Gastroentero. 2008, 14, 390-400.

28. Montrose, D.C.; Horelik, N.A.; Madigan, J.P. Anti-inflammatory effects of freeze-dried black raspberry powder in ulcerative colitis. Carcinogen. 2011, 32, 343-50.

29. Leite, M.S.; Pacheco, P.; Gomes, R.N. Mechanisms of increased survival after lipopolysaccharide-induced endotoxic shock in mice consuming olive oil-enriched diet. Shock. 2005, 23, 173-178.

30. Friesen, R.; Innis, S.M. Trans fatty acids in human milk in Canada declined with the introduction of trans fat food labelling. J. Nutr. 2006, 136, 2558-61.

31. Field, C.J.; Blewett, H.H; Proctor, S.; Vine, D. Human health benefits of vaccenic acid. Appl. Physiol. Nutr. Metab. 2009, 34, 979-91.

32. Tricon, S.; Burdge, G.C.; Jones, E.L.; Russell, J.J.; El-Khazen, S.; Moretti, E.; Hall, W.L.; Gerry, A.B.; Leake, D.S.; Grimble, R.F.; Williams, C.M.; Calder, P.C.; Yaqoob, P. Effects of dairy products naturally enriched with cis-9,trans-11 conjugated linoleic acid on the blood lipid profile in healthy middle-aged men. Am. J. Clin. Nutr. 2006, 83, 744-53.

33. Gebauer, S.K.; Chardigny, J.M.; Jakobsen, M.U.; Lamarche, B.; Lock, A.L.; Proctor, 
S.D.; Baer, D.J.; Lock, A.L. Effects of ruminant trans fatty acids on cardiovascular disease and cancer: a comprehensive review of epidemiological, clinical, and mechanistic studies. Adv. Nutr. 2011, 2, 332-54.

34. Laake, I.; Carlsen, M.H.; Pedersen, J.I.; Weiderpass, E.; Selmer, R.; Kirkhus, B.; Thune, I.; Veierød, M.B. Intake of trans fatty acids from partially hydrogenated vegetable and fish oils and ruminant fat in relation to cancer risk. Int. J. Cancer. 2013, 132, 1389-403.

35. Wang, Y.; Liu, J.; Ruth, M.R.; Goruk, S.D.; Reaney, M.J.; Glimm, D.R.; Vine, D.F.; Field, C.J.; Proctor, S.D. Trans-11 vaccenic acid dietary supplementation induces hypolipidemic effects in JCR:LA-cp rats. J. Nutr. 2008, 138, 2117-22. 